\title{
The Use of Facemasks During the COVID-19 Pandemic by the Brazilian Population
}

This article was published in the following Dove Press journal:

Journal of Multidisciplinary Healthcare

\author{
Paula Cotrin' \\ Amelia Cristine Bahls' \\ Daniella de Oliveira da Silva (D) ${ }^{2}$ \\ Valquiria Mendes Pereira \\ Girão iD ${ }^{2}$ \\ Célia Regina Maio \\ Pinzan-Vercelino ${ }^{2}$ \\ Ricardo Cesar Gobbi de Oliveira' \\ Renata Cristina Oliveira' \\ Maria Dalva de Barros \\ Carvalho ${ }^{3}$ \\ Sandra Marisa Pelloso ${ }^{3}$ \\ Fabricio Pinelli Valarelli (D) ${ }^{\prime}$ \\ Karina Maria Salvatore \\ Freitas (D) ${ }^{\prime}$ \\ 'Department of Dentistry, Ingá \\ University Center Uningá, Maringá, \\ Paraná, Brazil; ${ }^{2}$ Department of Dentistry, \\ University Ceuma, São Luís, Maranhão, \\ Brazil; ${ }^{3}$ Department of Health Sciences, \\ Maringá State University, Maringá, Brazil
}

Correspondence: Karina Maria Salvatore Freitas

Ingá University Center Uningá, Rod PR

317, 6II4 - 87035-510, Maringá, Paraná, Brazil

Tel +55 I4991026446

Email kmsf@uol.com.br
Objective: To evaluate the use of facemasks by the Brazilian population during the COVID19 pandemic.

Materials and Methods: This cross-sectional study involved 1277 participants who answered a web-based open survey with questions about the use of facemasks during the COVID-19 pandemic. Descriptive statistics with percentages was performed, and the responses were analyzed with chi-square and independent t-tests.

Results: A total of 1277 answered the questionnaire, and most participants were female (81.8\%). Almost all the participants (99.1\%) reported wearing facemasks, and $34.2 \%$ are wearing just because it is mandatory; $65.8 \%$ would continue to wear masks even if it was not mandatory. Most subjects (50.4\%) believe that masks' use effectively prevents infection by the novel coronavirus. Reusable fabric facemasks are the most used by the participants $(49.5 \%)$. Almost all subjects were wearing masks to go to crowded and public places. Most respondents $(67.3 \%)$ are bothered with the use of facemasks, and the most cited reason for the discomfort was feeling trapped or suffocated (58.9\%).

Discussion: The use of facemasks can help prevent the COVID-19, but it is most effective at reducing the spread of the virus when the general population's compliance is high. Some factors that limit the population's compliance with the use of masks are discomfort and a sense of embarrassment. Media campaigns and public health promotion activities supported by governmental agencies can increase the use of facemasks by the population.

Conclusion: The mean level of anxiety with the COVID-19 pandemic was 6.18. Almost all the participants were wearing facemasks, and they believe that its use effectively prevents infection by the novel coronavirus. Reusable fabric facemasks are the most used by the participants. Almost all subjects were wearing masks to go to crowded and public places. The great majority of the participants feel more protected with the use of facemasks.

Keywords: COVID-19, pandemics, masks, respiratory protective devices

\section{Introduction}

The COVID-19 pandemic, the disease caused by the novel coronavirus, is wellknown for all populations suffering to control the outbreak. Worldwide, as of September 30, 2020, there are more than 33 million infected people and more than 1 million deaths from COVID-19. In Brazil, the COVID-19 outbreak is still not under control, and the number of cases is still rising or maintained, depending on the Brazilian region. Brazil is in a critical situation, with 4,777,522 of confirmed cases and 142,921 deaths by COVID-19. ${ }^{1}$

It is known that severe acute respiratory syndrome coronavirus (SARS-CoV) is predominantly transmitted through direct or indirect contact with mucous membranes 
in the eyes, mouth, or nose. ${ }^{2}$ There is still no effective pharmaceutical intervention or vaccine to cure or prevent coronavirus infection.

In this context, non-pharmaceutical interventions (including border restrictions, quarantine and isolation, distancing, hand hygiene and changes in population behavior) are associated with the reduced transmission of COVID-19., Additionally, facemasks and facemasks plus hand hygiene may prevent infection in community settings. 5,6

The global spread of COVID-19 in early 2020 has significantly increased the demand for facemasks around the world. ${ }^{7}$ This caused a shortage of personal protective equipment (PPE) mainly because the general population gets started to use and stock PPE, fearing the contamination without following national guidelines. ${ }^{8}$ Latin America's shortages are compounded by a fundamental lack of preparedness and a lack of manufacturing resources to make PPE or ventilators. ${ }^{9}$ However, these countries are receiving global support and help to face the pandemic and these challenges. ${ }^{9}$

The use of facemasks in public places and business closed spaces is compulsory in many countries. ${ }^{10}$ The purpose of wearing masks is to reduce the spread of respiratory droplets containing viruses, preventing infected people from transmitting the virus to others and offering protection to healthy people against infection. ${ }^{7,11}$ Studies show that the mask acts as a temporal low pass filter, smoothens the droplet rate over time, and reduces the overall transmission. ${ }^{3,7}$

Systematic reviews about the use of facemasks indicate a reduction of the relative risk for infection ranging from 6 to $80 \%$, including for several types of coronavirus infection (COVID-19, SARS, MERS). ${ }^{12,13}$ This wide range of results might be a result of different criteria in the selection of studies, population, and probably the type of facemask. For the COVID-19 specifically, the evidence of prevention of contamination is low because it was based on observational studies with a high risk of bias. ${ }^{13}$ However, facemasks are physical barriers, cheap, and efficient in reducing short distance transmission through direct or indirect contact and droplet emission. ${ }^{11,12,14-16}$ Despite the uncertainty of infection control with the use of masks, the possible risk reduction must be considered in the context of the local epidemiology. ${ }^{13}$

This way, in Brazil, the public health measures to implement of facemask is more crucial due to the higher baseline risk for transmission. ${ }^{17}$ Mandatory use of facemask in public places during the COVID-19 pandemic caused the worsening in the global shortage of commercial supplies and led to the widespread use of homemade masks and mask alternatives, ${ }^{7}$ and this have changed the Brazilians population' habits. From a public policy perspective, there are concerns about the efficacy and the discomfort of prolonged use facemasks, which have led the population to a wide variation adherence to the government's recommendations; some people are not using facemasks, and others are using as recommended.

Therefore, this study aimed to evaluate the compliance, opinion and behavior of the Brazilian population about the use of masks during the COVID-19 pandemic.

\section{Materials and Methods}

This cross-sectional study was approved by the local Human Research Ethics Committee (protocol number: 4.079.866).

A structured questionnaire was developed according to the CHERRIES recommendations ${ }^{18}$ and tested on a pilot population before its administration in this study. The pilot study was undertaken with 30 laypeople to evaluate the questions' clarity and the language used. Some words were rewritten with synonyms so that the individuals were more likely to understand. The pilot study participants were not included in the main study.

The web-survey was prepared in Google Forms, and the link was posted on Facebook, Instagram, Twitter and sent by WhatsApp by the authors. In the introduction of the questionnaire, the subjects were informed about the study's objectives and gave their informed consent agreeing to participate. The approximate time for answering the questionnaire of 5 minutes was also informed.

The online survey was available for responses for 7 days, from July 25 to July 31 , 2020. The questionnaire was anonymous; no personal identification was requested. Since the original questionnaire was an open survey, a sample size calculation was not performed, and it was not possible to determine a response rate.

The questionnaire contained 17 multiple-choice questions, including participants' characteristics (sex, age, region of residence, level of education and family income) and questions about the use of facemasks during the COVID-19 pandemic (Figure 1). The approximate time for the answer to the questionnaire was informed, being about five minutes. Before sending the response to the questionnaire, participants could change their answers many times as they wish.

After data was collected, an excel spreadsheet was assembled for statistical analysis. No duplicate response control tool was used, but if identical responses in the 
Q1. How old are you?

Q2. Sex: () Male () Female

Q3. In which Brazilian region do you live?

Q4. What is you level of education? ( ) Elementary school ( ) High school ( ) University graduation ( ) Postgraduation degree

Q5. What is your monthly family income? ( ) Less than 1 minimum wage

() Between 1 and 2 minimum wages () Between 2 and 5 minimum wages

() More than 5 minimum wages

Q6. What is your level of anxiety about the COVID-19 pandemic? (0 indicates nothing anxious and 10 extremely anxious) () 0 () 1 () 2 () 3 () 4 () 5 () 6 () 7 () 8 () 9 () 10

Q7. Are you or a family member a health professional? () Yes () No

Q8. Are you wearing facemask during the pandemic? () Yes () No

Q9. If so, are you wearing the facemask just because it is mandatory?

() Yes () No, I would continue to wear it even if it was not mandatory

Q10. Do you believe that the use of facemasks is effective in preventing contamination by the novel coronavirus?

() Yes () No () Partially

Q11. Are you wearing reusable fabric masks or disposable masks?

() Reusable fabric masks () Disposable masks () Both

Q12. If you are wearing reusable masks, how often do you wash it?

() I always wash it right after the use, when I get home, even when I wear it for a short time ( ) Everyday

() Twice or three times a week () Once a week

() I never washed my mask

Q13. Please indicate in which locations or during which activities you are wearing or not a mask:

Responses: () Yes ( ) No ( ) I do not go to this place or perform this activity

a) Business offices, supermarkets, pharmacies, shops

b) Malls and wide closed locations

c) Health facilities such as medical and dental offices

d) House of family members or close friends

e) Walking outdoor

f) To practice outdoor exercises

g) To practice exercises in closed places

h) Driving a car

i) In public transportation

j) To receive someone who comes to your home

I) Elevators and public garages

Q14. Do you feel more protected with the use of facemasks? () Yes ( ) No

Q15. Would you wear a facemask during the pandemic in living environments with other people, even if it was not mandatory? ( ) Yes ( ) No

Q16. Does wearing a mask bother you? ( ) Yes () No

Q17. If so, what is the reason for the discomfort? (select all that apply)

() I feel my breath

() I feel trapped, suffocated

() I feel shortness of breath

() I feel discomfort in the ears due to the elastics

() I find it very unaesthetic to use a mask

( ) I had dermatitis/skin problems due to the use of the mask

() The mask fogs up my glasses

() I have a respiratory allergy, sinusitis

() It hinders communication between people

() Other:

Figure I Questionnaire applied. 

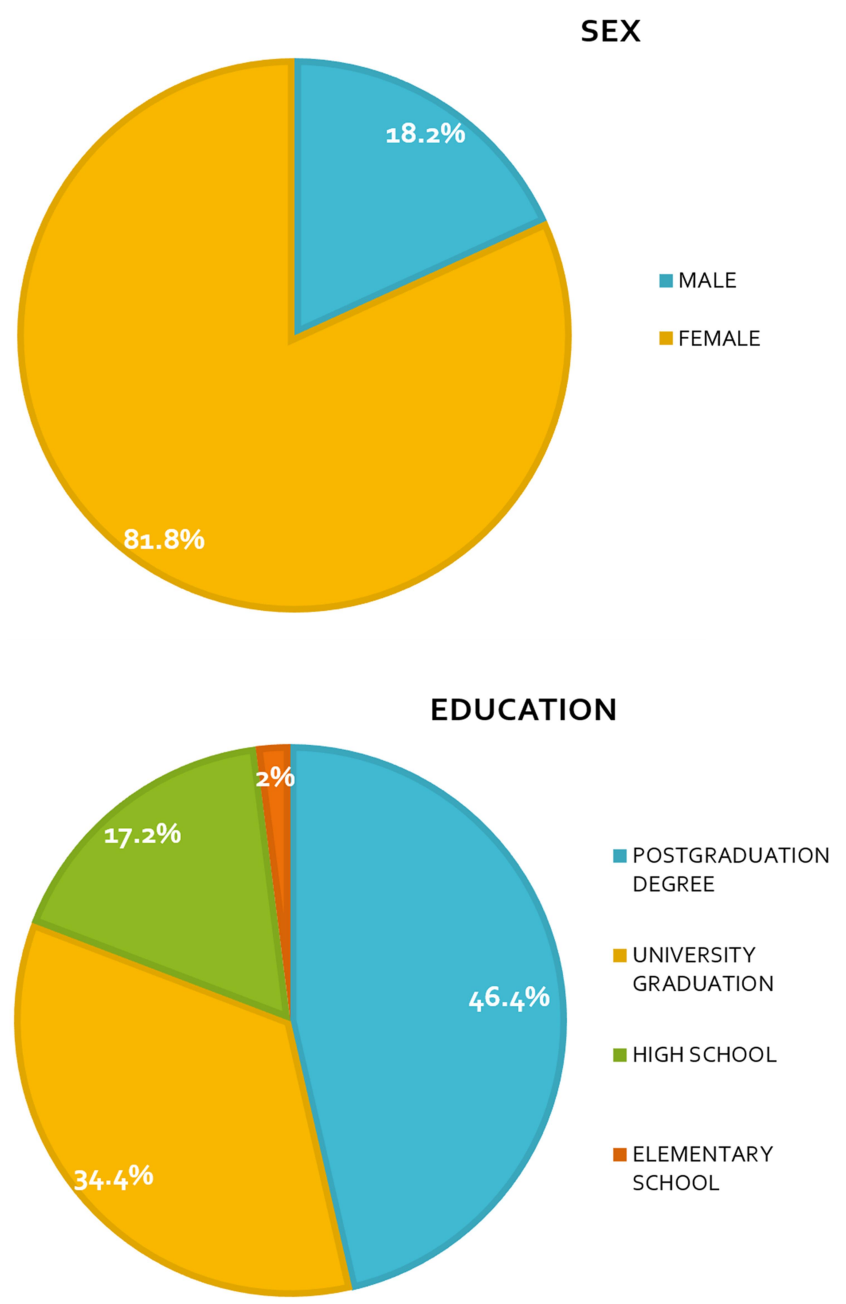

Figure 2 Demographics and sample characteristics.

sequence were observed, one was excluded. The answers and data obtained were stored by the researchers and used only for this study.

To assess the intrarater agreement, question 8 (Are you wearing facemasks during the pandemic?) was asked twice throughout the questionnaire. This question was chosen because it presents only two choices: yes or no, and was an important question for the survey. Kappa statistics was used to verify the intrarater agreement, and the result showed a coefficient of 0.96 , which is considered an excellent agreement. $^{19}$

Descriptive statistics were performed with percentages for each question/answer. Chi-square tests were used to compare the answers between health professionals and persons with family members working with health care and the laypeople.

Statistical analysis was performed with SPSS software (version 20, IBM, Armonk, NY, USA) and the results were considered significant at $\mathrm{P}<0.05$.
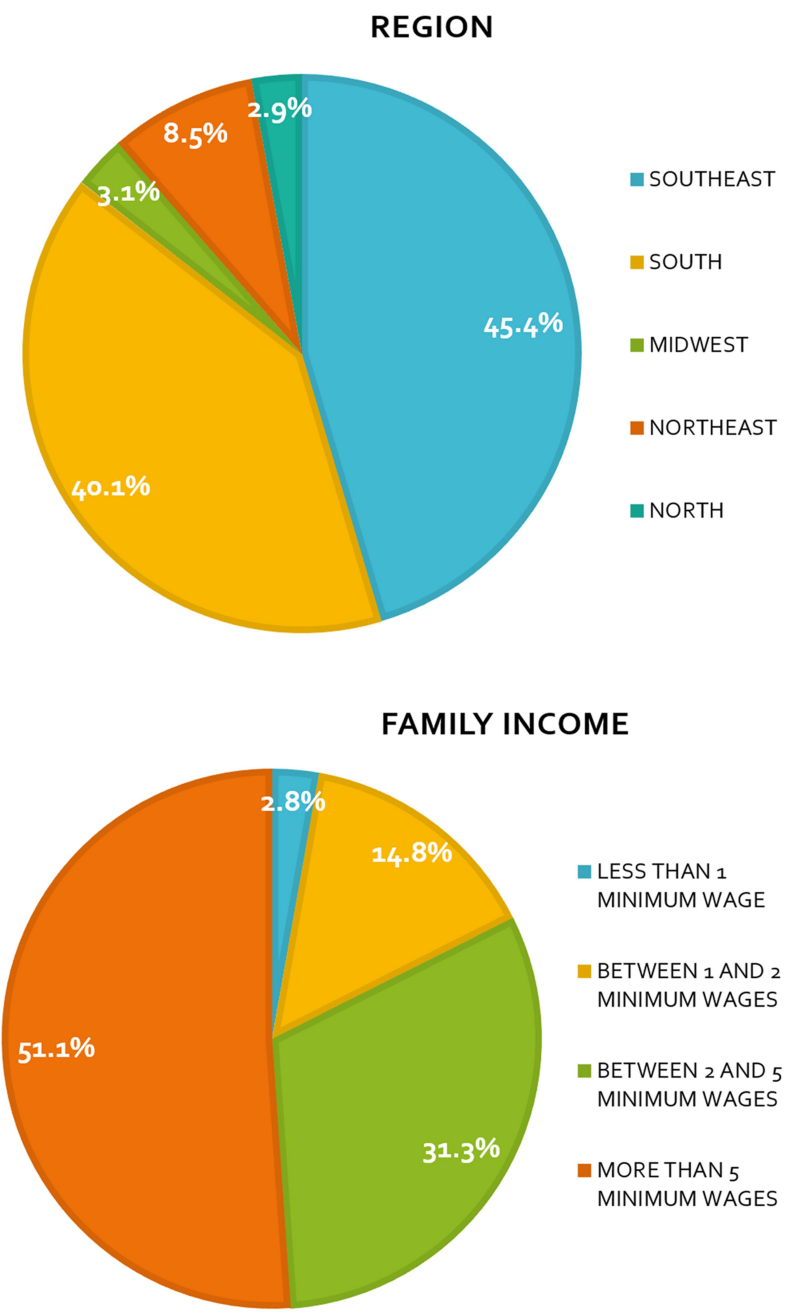

\section{Results}

A total of 1277 individuals participated in the survey. Demographics are shown in Figure 2. The mean age of the respondents was 39.03 years (SD 12.02). Most participants were females $(81.8 \%)$, from the southeast (45.4\%) and south $(40.1 \%)$ Brazilian regions, had a postgraduation degree $(46.4 \%)$ and had family income more than 5 minimum wages (51.1\%) (Figure 2). The mean level of anxiety about the COVID-19 pandemic was 6.18 (SD 2.79). Most of the respondents $(66.4 \%)$ were health professionals or had family members working in healthcare. This healthrelated group presented more males, a higher education level, a greater family income, and was less anxious with the pandemic than the laypeople group (Table 1).

Almost all the participants (99.1\%) reported wearing facemasks during the COVID-19 pandemic. However, $34.2 \%$ are wearing masks just because it is mandatory; $65.8 \%$ would continue to wear masks even if it was not 
mandatory. More lay people reported that they would not wear masks if not mandatory (Table 1). Most subjects (50.4\%) believe that the use of masks is effective in preventing infection by the novel coronavirus; $43.9 \%$ think that it prevents partially, and $5.7 \%$ believe that the use of masks does not prevent contamination by COVID-19.

Reusable fabric facemasks are the most used by the participants $(49.5 \%) ; 43.1 \%$ are wearing disposable masks, and $7.4 \%$ are wearing both types of facemasks. From the subjects that are wearing reusable fabric masks, $44.3 \%$ always wash it right after the use, when they get home, even if the mask was used for a short time; $29.2 \%$ wash it every day, $12.8 \%$ twice to three times a week, $9.6 \%$ once a week and only $4.1 \%$ reported to had never washed their facemasks.

Almost all subjects were wearing masks to go to business offices, supermarkets, pharmacies, shops (99.5\%), and health facilities such as medical and dental offices (93.1\%). Most participants were wearing masks to go to malls and wide closed locations (68.4\%), walking outdoor $(74.5 \%)$, to receive someone who comes to your home (67\%) and inside elevators and public garages (77.7\%). The minority of subjects were wearing masks to go to the house of family members or close friends (44.6\%), to practice exercises outdoor $(48 \%)$ or in closed places $(47.8 \%)$ and while driving a car $(45.3 \%)$. In public transportation, only $3.8 \%$ of the participants did not wear masks; $46.4 \%$ use masks and, $49.8 \%$ do not use public transportation (Figure 3).

The great majority of the participants $(83.1 \%)$ feel more protected with the use of facemasks, but the health-related group feels more protected than the laypeople (Table 1). Eighty-three percent of the subjects would wear a mask during the pandemic in certain living environments with other people, even if it was not mandatory. Health professions and related subjects reported more that would wear a mask in certain environments, even if it was not mandatory (Table 1).

Most respondents $(67.3 \%)$ reported that the use of masks bothers them in some way; the most cited reasons for the discomfort was: $58.9 \%$ feel trapped, suffocated, $55.1 \%$ feel shortness of breath, $49.8 \%$ feel discomfort in the ears due to the elastics, and $43.9 \%$ reported that the use of mask fogs up the glasses. Other reasons were to feel the own breath $(11.1 \%)$, dermatitis/skin problems $(6.6 \%)$ and esthetic issues with the use of masks (5.3\%). Laypeople reported more discomfort with the use of masks than health-related subjects (Table 1).

\section{Discussion}

This survey's findings showed that despite some concerns and issues, the Brazilian population is wearing facemasks. These data also suggest that people believe that wearing facemasks protect against COVID-19 infection.

Because clear water, soap and sanitizer alcohol gel are sometimes unavailable, people can be infected through hand-mouth, hand-nose, or hand-eye contact before handwashing, ${ }^{14,20}$ so the use of facemasks have gained great importance lately, being of mandatory use for coronavirus prevention. ${ }^{10}$ As this generated a huge change in the daily routine of the population, this study aimed to assess their adaptation and behavior concerning the use of masks. To the best of our knowledge, this is the first study that evaluated the use of facemasks by the community in Brazil.

Open surveys do not allow calculation of the response rate. Our sample presented a satisfactory number of participants since the subjects were from all Brazilian regions, with a great age range (excluding children and adolescents below 16 years), with different education degrees and family incomes. However, the sample is not necessarily generalizable, and this is a limitation of our study. Nevertheless, open surveys generate interesting data, especially when the objective of the study is a qualitative analysis to analyze the current trends of a specific issue. ${ }^{21}$ Besides, the internet nowadays has great representativeness in society and population. ${ }^{22}$ This way, the sample obtained is adequate and satisfactory, allowing reliable assumptions about the Brazilian population's opinion and behavior about the use of masks during the COVID-19 pandemic.

Females were the majority in the present study. This was already expected since women participate more in answering surveys. ${ }^{23-26}$ The mean level of anxiety about the COVID-19 pandemic was 6.18 (SD 2.79). Recent studies showed that depressive and anxiety symptoms had been reported in 16 to $28 \%$ of the subjects screened during the COVID-19 pandemic and these responses affect both the general public and healthcare workers. ${ }^{27,28}$ Uncertain prognoses and uncertainty about the future, the imposition of unfamiliar public health measures that infringe on personal freedoms, large and growing financial losses, and conflicting messages from authorities are among the major stressors that undoubtedly contribute to widespread the emotional distress and increased risk of anxiety during the pandemic. ${ }^{29,30}$ 
Table I Comparison Between the Groups of Health Professionals or Persons Who Had a Family Member Working in Healthcare and the Laypeople Group

\begin{tabular}{|c|c|c|c|}
\hline \multirow[t]{2}{*}{ Questions } & $\begin{array}{l}\text { Health-Related } \\
\text { Group } n=848\end{array}$ & $\begin{array}{l}\text { Laypeople } \\
n=429\end{array}$ & \multirow[t]{2}{*}{ p-value } \\
\hline & $\begin{array}{l}\text { Mean (SD) or } \\
n(\%)\end{array}$ & $\begin{array}{l}\text { Mean (SD) } \\
\text { or } n(\%)\end{array}$ & \\
\hline Age (years) & $38.79(12.17)$ & $39.50(11.70)$ & 0.315 \\
\hline $\begin{array}{l}\text { Sex } \\
\text { Female } \\
\text { Male }\end{array}$ & $\begin{array}{l}677(79.8 \%) \\
17 \mid(20.2 \%)\end{array}$ & $\begin{array}{l}367(85.5 \%) \\
62(14.5 \%)\end{array}$ & $\begin{array}{l}\chi^{2}=6.23 \mathrm{DF}=1 \\
\mathrm{p}=0.013^{*}\end{array}$ \\
\hline $\begin{array}{l}\text { Level of education } \\
\text { Elementary school } \\
\text { High school } \\
\text { University graduation } \\
\text { Postgraduation degree }\end{array}$ & $\begin{array}{l}6(0.7 \%) \\
88(10.4 \%) \\
285(33.6 \%) \\
469(55.3 \%)\end{array}$ & $\begin{array}{l}20(4.6 \%) \\
132(30.8 \%) \\
154(35.9 \%) \\
123(28.7 \%)\end{array}$ & $\begin{array}{l}\chi^{2}=134.67 \mathrm{DF}=3 \\
\mathrm{p}=0.000 *\end{array}$ \\
\hline $\begin{array}{l}\text { Family income } \\
\text { Less than I minimum wage } \\
\text { Between I and } 2 \text { minimum wages } \\
\text { Between } 2 \text { and } 5 \text { minimum wages } \\
\text { More than } 5 \text { minimum wages }\end{array}$ & $\begin{array}{l}14(1.7 \%) \\
100(11.8 \%) \\
241(28.4 \%) \\
493(58.1 \%)\end{array}$ & $\begin{array}{l}21(4.9 \%) \\
89(20.7 \%) \\
159(37.1 \%) \\
160(37.3 \%)\end{array}$ & $\begin{array}{l}\chi^{2}=57.36 \mathrm{DF}=3 \\
\mathrm{p}=0.000 *\end{array}$ \\
\hline Level of anxiety with the pandemic (score) & $6.06(2.67)$ & $6.43(2.97)$ & $0.027^{*}$ \\
\hline $\begin{array}{l}\text { Are you wearing facemask during the pandemic? } \\
\text { Yes } \\
\text { No }\end{array}$ & $\begin{array}{l}842(99.2 \%) \\
6(0.8 \%)\end{array}$ & $\begin{array}{l}424 \text { (98.8\%) } \\
5(1.2 \%)\end{array}$ & $\begin{array}{l}\chi^{2}=0.69 \mathrm{DF}=1 \\
\mathrm{p}=0.402\end{array}$ \\
\hline $\begin{array}{l}\text { If so, are you wearing the facemask just because it is mandatory? } \\
\text { Yes } \\
\text { No }\end{array}$ & $\begin{array}{l}267(31.5 \%) \\
581(68.5 \%)\end{array}$ & $\begin{array}{l}176(4 \mid \%) \\
253(59 \%)\end{array}$ & $\begin{array}{l}\chi^{2}=11.44 \mathrm{DF}=1 \\
\mathrm{p}=0.000 *\end{array}$ \\
\hline $\begin{array}{l}\text { Do you believe that the use of facemasks is effective in preventing c } \\
\text { the novel coronavirus? } \\
\text { Yes } \\
\text { No } \\
\text { Partially }\end{array}$ & $\begin{array}{l}434(51.2 \%) \\
41(4.8 \%) \\
373(44 \%)\end{array}$ & $\begin{array}{l}210(49 \%) \\
32(7.5 \%) \\
187(43.6 \%)\end{array}$ & $\begin{array}{l}\chi^{2}=3.72 \mathrm{DF}=2 \\
\mathrm{p}=0.155\end{array}$ \\
\hline $\begin{array}{l}\text { Do you feel more protected with the use of facemasks? } \\
\text { Yes } \\
\text { No }\end{array}$ & $\begin{array}{l}722(85.1 \%) \\
126(14.9 \%)\end{array}$ & $\begin{array}{l}339(79 \%) \\
90(21 \%)\end{array}$ & $\begin{array}{l}\chi^{2}=7.59 \mathrm{DF}=1 \\
\mathrm{p}=0.006^{*}\end{array}$ \\
\hline $\begin{array}{l}\text { Would you wear a facemask during the pandemic in living environm } \\
\text { people, even if it was not mandatory? } \\
\text { Yes } \\
\text { No }\end{array}$ & $\begin{array}{l}727(85.7 \%) \\
121(14.3 \%)\end{array}$ & $\begin{array}{l}333(77.6 \%) \\
96(22.4 \%)\end{array}$ & $\begin{array}{l}\chi^{2}=13.28 \mathrm{DF}=1 \\
\mathrm{p}=0.000 *\end{array}$ \\
\hline $\begin{array}{l}\text { Does wearing a mask bother you? } \\
\text { Yes } \\
\text { No }\end{array}$ & $\begin{array}{l}538(63.4 \%) \\
310(36.6 \%)\end{array}$ & $\begin{array}{l}322(75.1 \%) \\
107(24.9 \%)\end{array}$ & $\begin{array}{l}\chi^{2}=7.59 \mathrm{DF}=1 \\
\mathrm{p}=0.006^{*}\end{array}$ \\
\hline
\end{tabular}

Note: *Statistically significant at $p<0.05$.

Most of the respondents (66.4\%) were health professionals or had family members working in healthcare. This health-related group presented more males, a higher education level, a greater family income, and was less anxious with the pandemic than the laypeople group (Table 1). It was expected since it is known that higher income is beneficial for psychological well-being. ${ }^{31,32}$ People with higher income are happier, more satisfied with their lives, 


\section{In which locations or during which activities are you wearing or not a mask?}

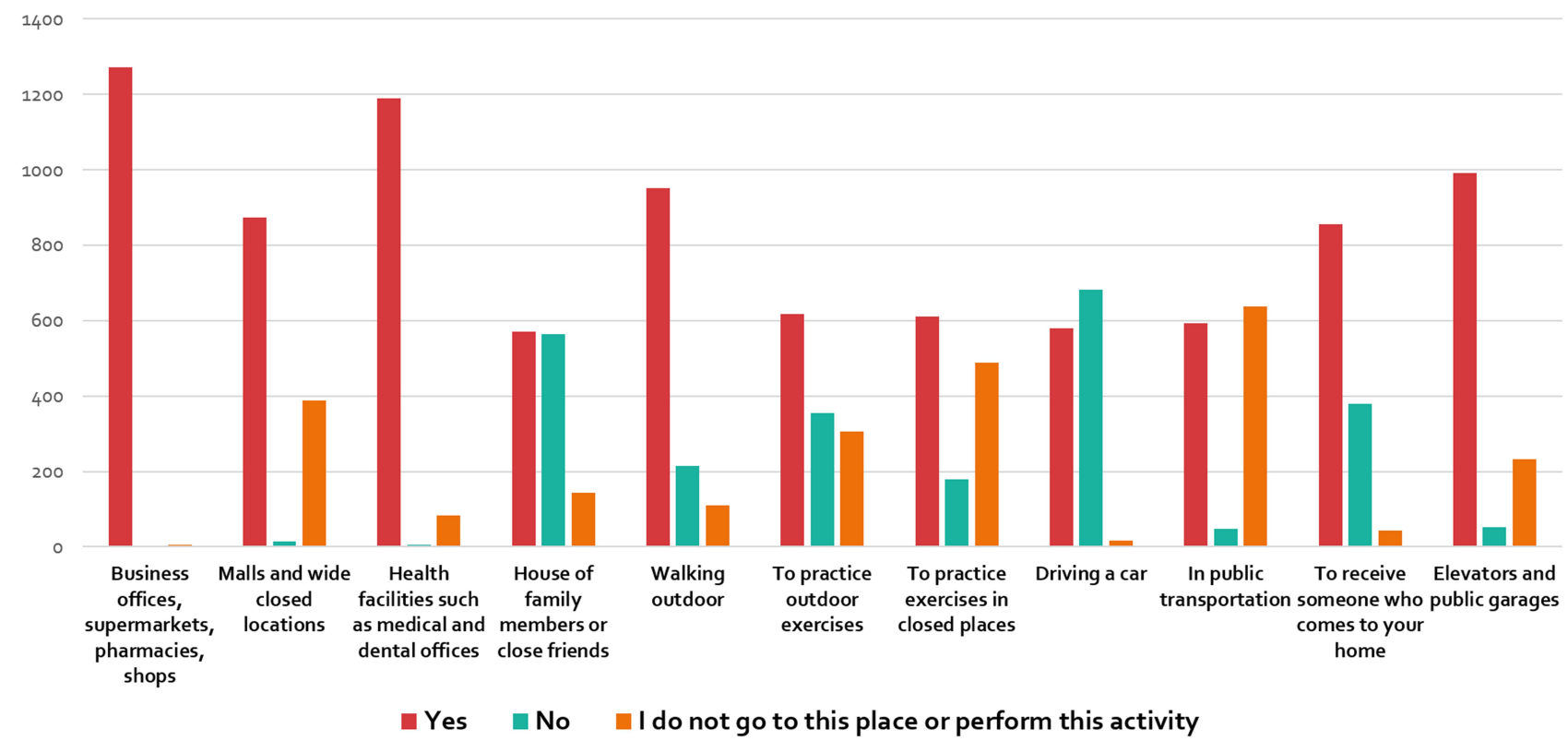

Figure 3 Responses to the questions 13: In which locations or during which activities you are wearing or not a mask?

material status, health, achievement, economic situation, and social conditions. ${ }^{33}$

When the questionnaire was sent to the subjects, the use of facemask had been advised or compulsory in Brazil for more than three months, and the coronavirus pandemic was at the outbreak's rising curve. A recent survey showed that N95 masks, medical masks, and homemade masks made of 4-layer kitchen paper and 1-layer fabric could block $99.98 \%, 97.14 \%$, and $95.15 \%$ of the virus in aerosols, respectively. ${ }^{20}$ Moreover, the use of masks can enhance vigilance, prevent direct hand-mouth or handnose contact, and reduce air contamination of pathogens from infected people. ${ }^{20}$ Recent studies demonstrated a decrease in psychopathological symptoms after the compulsory use of masks in public spaces ${ }^{34}$ and workplaces. ${ }^{35}$ Facemasks increased the level of perceived self-protection as well as improved well-being and mental health. ${ }^{34}$

Almost all the participants (99.1\%) reported wearing facemasks during the COVID-19 pandemic. This result is in agreement with the results of Leung et $\mathrm{al}^{3}$ conducted in Hong Kong in the early stage of the pandemic. However, $34.2 \%$ are wearing masks only because it is mandatory. It is known that compliance with the use of facemasks is affected by the perception of risk. ${ }^{36}$ During a pandemic, it would be expected that compliance improves. Models suggest that public mask wearing is most effective at stopping the spread of the virus when compliance is high. ${ }^{37}$ The balance between risk perception and discomfort affects individual decisions to use facemasks. ${ }^{5}$ When the risk of infection is thought to be high, acceptance and compliance with interventions to prevent infection are generally higher. ${ }^{38} \mathrm{~A}$ common policy response to this is to ensure compliance by using laws and regulations, which is still not completely defined in Brazil.

Reusable fabric facemasks are the most used by the participants (49.5\%). It was expected since there is currently a global shortage of N95 and FFP2 respirators, as well as disposable surgical facemasks; the use of simple fabric masks seems to be a smart and low-cost solution. Howard et $\mathrm{al}^{37}$ recommend adopting reusable fabric mask wearing, as an effective form of infection control, in conjunction with hygiene, distancing, and contact tracing strategies.

Almost all subjects were wearing masks to go to business offices, supermarkets, pharmacies and public transportation (Figure 3), and the great majority reported feeling more protected while using facemasks (Table 1). Another finding was that the health-related group feels more protected than the laypeople (Table 1). The available evidence suggests that near-universal adoption of nonmedical masks in public places, combined with complementary health measures, could successfully reduce the community spread. ${ }^{37}$ One can think that wearing masks can give the false feeling that the public is completely 
protected from the virus, and within this context, it could be speculated that the health-related group was feeling more protected due to their greater knowledge related to infectious diseases and also the usual routine of wearing masks. Nevertheless, Chu et $\mathrm{al}^{12}$ did not detect any striking differences in the effectiveness of facemask use between community settings and health care settings. However, the existing evidence regarding the efficacy of using facemasks is sparse, and findings are inconsistent. While some studies support the use of respiratory protection, ${ }^{12,20,37,39}$ they also evidence that this intervention did not afford complete protection from infection. ${ }^{12}$ Therefore, the objective of this study was not to evaluate the effectiveness of the facemask use but to evaluate if and how the population is using it.

The health professionals and related subjects reported more that would wear a mask even if it was not mandatory (Table 1), maybe because these individuals or their family members are frequently more in contact with possible infected people than the other group, and need to be more cautious and prevent against contamination. Besides that, for frontline healthcare workers, wearing masks is necessary as it empowers them to fight the deadly COVID-19 with less fear and anxiety of contracting the disease. ${ }^{40}$ However, "the mask" is perhaps the mostpowerful psychological symbol for the common people.

Most respondents (67.3\%) reported that masks bother them somehow, and the main reason reported for the discomfort was the sensation of feeling trapped or suffocated. Besides that, laypeople reported more discomfort with the use of masks than health-related subjects (Table 1). A recent study ${ }^{41}$ showed that the use of masks ends up being a new social norm. The higher the frequency of people wearing masks in the displayed social group, the less strange they felt about themselves because the mere exposure to social groups wearing masks reduces the strange feeling of wearing a mask. ${ }^{41}$ According to MacIntyre et $\mathrm{al}^{5}{ }^{5}$ discomfort is not the sole determinant of compliance, which is also influenced by cultural factors, risk perception, and experience of serious outbreaks such as SARS. In Brazil, the cultural factors associated with the bad example of the President who appears in public places without wearing a mask can lead to less adherence by people to the use of masks as recommended by health authorities.

The acknowledgment of the uncertainty about the quality of evidence and understanding the difference between relative and absolute reductions in risk of contamination is the key to sort out the many questions and the confusion about the use of facemasks. ${ }^{13}$ Despite that, exceptional situations require exceptional measures. In front of the huge challenge to mitigate the pandemic, many daily habits were altered due to the COVID-19 pandemic and one of them is the use of masks, even with all the issues inherent to it.

Based on several previous findings, the use of facemasks can help prevent the COVID-19 and other infections. ${ }^{6,39,42}$ However, the use of facemasks by the general public is most effective at reducing the spread of the virus when compliance is high. ${ }^{37}$ And compliance is related to the comfort of people wearing it. ${ }^{6}$ Besides, individuals are more likely to wear facemasks due to the perceived susceptibility and severity of being infected with life-threatening diseases. ${ }^{6}$

Some factors that limit the population's compliance with the use of masks are discomfort and the sense of embarrassment. ${ }^{6}$ Media campaigns and public health promotion activities supported by governmental agencies can increase the use of facemasks by the population. ${ }^{6,37,43}$ This study will give policymakers a broader view of how the general public responds to the COVID-19 pandemic and changing their lifestyles.

\section{Conclusion}

The mean level of anxiety with the COVID-19 pandemic was 6.18. Almost all the participants were wearing facemasks, and they believe that its use effectively prevents infection by the novel coronavirus. Reusable fabric facemasks are the most used by the participants. Almost all subjects were wearing masks to go to crowded and public places, and most participants feel more protected with the use of facemasks.

\section{Disclosure}

The authors report no conflicts of interest for this work.

\section{References}

1. Johns Hopkins University. COVID-19 dashboard by the Center for Systems Science and Engineering (CSSE) at Johns Hopkins University (JHU). 2020. Available from: https://coronavirus.jhu.edu/map.html. Accessed September 30, 2020.

2. Peiris JS, Yuen KY, Osterhaus AD, Stohr K. The severe acute respiratory syndrome. N Engl J Med. 2003;349(25):2431-2441. doi:10.1056/ NEJMra032498

3. Leung NHL, Chu DKW, Shiu EYC, et al. Respiratory virus shedding in exhaled breath and efficacy of face masks. Nat Med. 2020;26 (5):676-680. doi:10.1038/s41591-020-0843-2 
4. Huynh TLD. The COVID-19 containment in Vietnam: what are we doing? J Glob Health. 2020;10(1):010338. doi:10.7189/ jogh. 10.010338

5. MacIntyre CR, Chughtai AA. Facemasks for the prevention of infection in healthcare and community settings. BMJ. 2015;350:h694.

6. Sim SW, Moey KS, Tan NC. The use of facemasks to prevent respiratory infection: a literature review in the context of the health belief model. Singapore Med J. 2014;55(3):160-167.

7. Fischer EP, Fischer MC, Grass D, Henrion I, Warren WS, Westman E. Low-cost measurement of facemask efficacy for filtering expelled droplets during speech. Sci Adv. 2020;6(36):eabd3083.

8. Bhattacharya S, Hossain MM, Singh A. Addressing the shortage of personal protective equipment during the COVID-19 pandemic in India-A public health perspective. AIMS Public Health. 2020;7 (2):223-227. doi:10.3934/publichealth.2020019

9. Rubin R, Abbasi J, Voelker R. Latin America and its global partners toil to procure medical supplies as COVID-19 pushes the region to its limit. JAMA. 2020;324(3):217-219. doi:10.1001/jama.2020.11182

10. Huynh TLD. "If you wear a mask, then you must know how to use it and dispose of it properly!": a Survey Study in Vietnam. Rev Behav Econ. 2020;7(2):145-158. doi:10.1561/105.00000121

11. World Health Organization. Advice on the use of masks in the community, during home care and in health care settings in the context of the novel coronavirus (2019-nCoV) outbreak: interim guidance, 29 January 2020. 2020. Available from: https://apps.who. int/iris/handle/10665/330987. Accessed August 14, 2020.

12. Chu DK, Akl EA, Duda S, et al. Physical distancing, face masks, and eye protection to prevent person-to-person transmission of SARS-CoV-2 and COVID-19: a systematic review and meta-analysis. Lancet. 2020;395(10242):1973-1987. doi:10.1016/ S0140-6736(20)31142-9

13. Schunemann HJ, Akl EA, Chou R, et al. Use of facemasks during the COVID-19 pandemic. Lancet Respir Med. 2020;8(10):954-955. doi:10.1016/S2213-2600(20)30352-0

14. Cheng VC, Wong SC, Chuang VW, et al. The role of community-wide wearing of face mask for control of coronavirus disease 2019 (COVID-19) epidemic due to SARS-CoV-2. J Infect. 2020;81(1):107-114. doi:10.1016/j.jinf.2020.04.024

15. Greenhalgh T, Schmid MB, Czypionka T, Bassler D, Gruer L. Face masks for the public during the covid-19 crisis. BMJ. 2020;369: m1435. doi: $10.1136 /$ bmj.m1435

16. Eikenberry SE, Mancuso M, Iboi E, et al. To mask or not to mask: modeling the potential for face mask use by the general public to curtail the COVID-19 pandemic. Infect Dis Model. 2020;5:293-308.

17. Hamner L, Dubbel P, Capron I, et al. High SARS-CoV-2 attack rate following exposure at a choir practice - Skagit County, Washington, March 2020. MMWR Morb Mortal Wkly Rep. 2020;69(19):606-610. doi:10.15585/mmwr.mm6919e6

18. Eysenbach G. Improving the quality of web surveys: the checklist for reporting results of internet E-surveys (CHERRIES). J Med Internet Res. 2004;6(3):e34. doi:10.2196/jmir.6.3.e34

19. Landis JR, Koch GG. The measurement of observer agreement for categorical data. Biometrics. 1977;33(1):159-174. doi:10.2307/ 2529310

20. Ma Q-X, Shan H, Zhang H-L, Li G-M, Yang R-M, Chen J-M. Potential utilities of mask-wearing and instant hand hygiene for fighting SARS-CoV-2. J Med Virol. 2020;92(9):1567-1571. doi:10.1002/ jmv. 25805

21. Eysenbach G, Wyatt J. Using the internet for surveys and health research. J Med Internet Res. 2002;4(2):e13. doi:10.2196/jmir.4.2.e13

22. Houston JD, Fiore DC. Online medical surveys: using the Internet as a research tool. MD Comput. 1998;15(2):116-120.

23. Peloso RM, Pini NIP, Sundfeld Neto D, et al. How does the quarantine resulting from COVID-19 impact dental appointments and patient anxiety levels? Braz Oral Res. 2020;34:e84. doi:10.1590/ 1807-3107bor-2020.vol34.0084
24. Cotrin P, Peloso RM, Oliveira RC, et al. Impact of coronavirus pandemic in appointments and anxiety/concerns of patients regarding orthodontic treatment. Orthod Craniofac Res. 2020. doi:10.1111/ocr.12395

25. Peloso RM, Ferruzzi F, Mori AA, et al. Notes from the field: concerns of health-related higher education students in Brazil pertaining to distance learning during the coronavirus pandemic. Eval Health Prof. 2020;43(3):163278720939302.

26. Qiu J, Shen B, Zhao M, Wang Z, Xie B, Xu Y. A nationwide survey of psychological distress among Chinese people in the COVID-19 epidemic: implications and policy recommendations. Gen Psychiatry. 2020;33(2):e100213. doi:10.1136/gpsych-2020-100213

27. Rajkumar RP. COVID-19 and mental health: a review of the existing literature. Asian J Psychiatr. 2020;52:102066. doi:10.1016/j. ajp.2020.102066

28. Torales J, O’Higgins M, Castaldelli-Maia JM, Ventriglio A. The outbreak of COVID-19 coronavirus and its impact on global mental health. Int J Soc Psychiatry. 2020;66(4):317-320. doi:10.1177/ 0020764020915212

29. Pfefferbaum B, North CS. Mental health and the covid-19 pandemic. $N$ Engl J Med. 2020;383(6):510-512.

30. Kissler SM, Tedijanto C, Goldstein E, Grad YH, Lipsitch M. Projecting the transmission dynamics of SARS-CoV-2 through the postpandemic period. Science. 2020;368(6493):860-868 doi:10.1126/science.abb5793

31. Richards L, Paskov M. Social class, employment status and inequality in psychological well-being in the UK: cross-sectional and fixed effects analyses over two decades. Soc Sci Med. 2016;167:45-53. doi:10.1016/j.socscimed.2016.08.042

32. Cummins RA. Personal income and subjective well-being: a review. J Happiness Stud. 2000;1(2):133-158. doi:10.1023/A:1010079728426

33. Lipovcan LK, Brkljacic T, Sakic V. Monthly income and subjective well-being of croatian citizens. Croat Med J. 2007;48(5):727-733.

34. Szczesniak D, Ciulkowicz M, Maciaszek J, et al. Psychopathological responses and face mask restrictions during the COVID-19 outbreak: results from a nationwide survey. Brain Behav Immun. 2020;87:161-162. doi:10.1016/j.bbi.2020.05.027

35. Tan W, Hao F, McIntyre RS, et al. Is returning to work during the COVID-19 pandemic stressful? A study on immediate mental health status and psychoneuroimmunity prevention measures of Chinese workforce. Brain Behav Immun. 2020;87:84-92. doi:10.1016/j. bbi.2020.04.055

36. MacIntyre CR, Cauchemez S, Dwyer DE, et al. Face mask use and control of respiratory virus transmission in households. Emerg Infect Dis. 2009;15(2):233-241. doi:10.3201/eid1502.081166

37. Howard J, Huang A, Li Z, et al. Face masks against COVID-19: an evidence review. Preprints. 2020;2020040203.

38. Albano L, Matuozzo A, Marinelli P, Di Giuseppe G. Knowledge, attitudes and behaviour of hospital health-care workers regarding influenza A/H1N1: a cross sectional survey. BMC Infect Dis. 2014;14:208

39. Offeddu V, Yung CF, Low MSF, Tam CC. Effectiveness of masks and respirators against respiratory infections in healthcare workers: a systematic review and meta-analysis. Clin Infect Dis. 2017;65 (11):1934-1942.

40. Goh Y, Tan BYQ, Bhartendu C, Ong JJY, Sharma VK. The face mask: how a real protection becomes a psychological symbol during Covid-19? Brain Behav Immun. 2020;88:1-5. doi:10.1016/j. bbi.2020.05.060

41. Carbon -C-C The psychology of wearing face masks in times of the COVID-19 pandemic (April 24, 2020). Available at SSRN. 2020.

42. van der Sande M, Teunis P, Sabel R, Pai M. Professional and home-made face masks reduce exposure to respiratory infections among the general population. PLoS One. 2008;3(7):e2618. doi:10.1371/journal.pone.0002618

43. Huynh TL. The COVID-19 risk perception: a survey on socioeconomics and media attention. Econ Bull. 2020;40(1):758-764. 


\section{Publish your work in this journal}

The Journal of Multidisciplinary Healthcare is an international, peerreviewed open-access journal that aims to represent and publish research in healthcare areas delivered by practitioners of different disciplines. This includes studies and reviews conducted by multidisciplinary teams as well as research which evaluates the results or conduct of such teams or healthcare processes in general. The journal covers a very wide range of areas and welcomes submissions from practitioners at all levels, from all over the world. The manuscript management system is completely online and includes a very quick and fair peer-review system. Visit http://www.dovepress.com/testimonials. php to read real quotes from published authors. 